\title{
Otorhinolaryngology in the COVID-19 era: Are there significant differences between hospital-based and private practices?
}

\author{
Anasuya Guha ${ }^{1}$, Jan Plzak ${ }^{2}$, Petr Schalek ${ }^{1}$, and Martin Chovanec ${ }^{1}$ \\ ${ }^{1}$ Charles University Third Faculty of Medicine \\ ${ }^{2}$ Charles University First Faculty of Medicine
}

October 12, 2020

\begin{abstract}
Objectives The COVID-19 disease had an incredible impact on both hospital-based and private practices in the field of otorhinolaryngology and head and neck surgery. Practical issues faced by both types of practice were not well addressed in most studies. A national study was designed to address these issues. Design Prospective questionnaire-based study Setting Online google questionnaire sent to members of the Czech Society of Otorhinolaryngology and Head and Neck Surgery Participants All doctors practicing Otorhinolaryngology in Czech Republic with access to online link to questionnaire between 15th April and 26th April 2020. Main outcome measures Primary aims of the study was to evaluate any significant differences between the two types of practice in the field of Otorhinolaryngology. We formulated null hypotheses stating there were no statistical differences in the preparation and availability of personal protective equipment amongst both practices a month after the first cases of COVID-19 in Czech Republic. Statistical analyses including the Mann-Whitney U test were performed to test the hypotheses. Results Analysis and results were based on completion of the entire questionnaire by the doctors. There were no statistically significant differences between both the practices, however individual analyses of both the practices showed a different outcome. Conclusion Despite our statistical results, it was observed that private practices faced more deficits and were more financially vulnerable. They were also other issues reported by both practices that could compromise the care of patients, functioning of workplaces and support of doctors.
\end{abstract}

\section{Hosted file}

New BM Guha Guha_ORL in the COVID.pdf available at https://authorea.com/users/366505/ articles/486237-otorhinolaryngology-in-the-covid-19-era-are-there-significantdifferences-between-hospital-based-and-private-practices

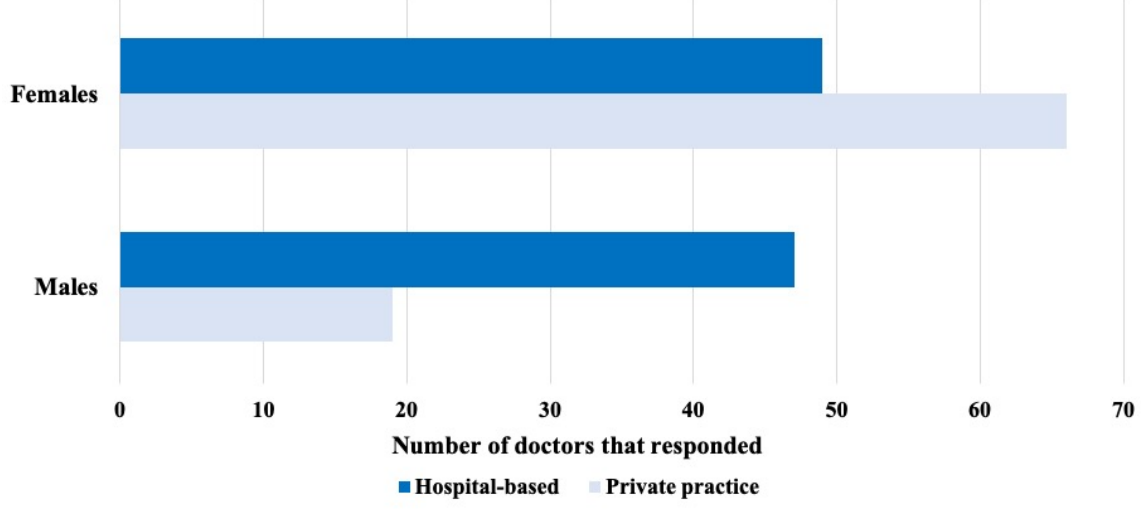



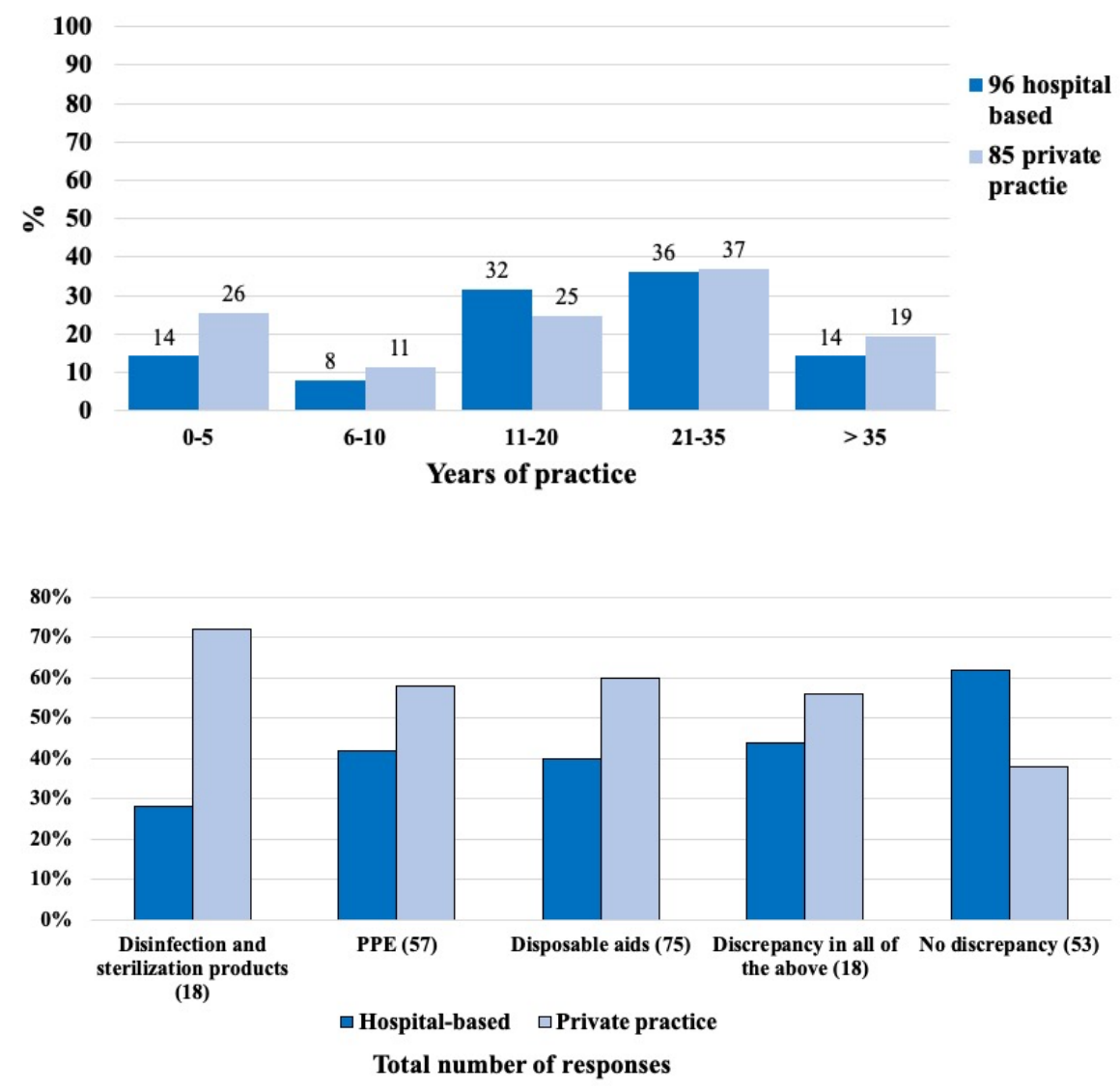

\section{Hosted file}

Table 1 modified Guha 2020_Results COVID-19 vs HB PP.pdf available at https://authorea. com/users/366505/articles/486237-otorhinolaryngology-in-the-covid-19-era-are-theresignificant-differences-between-hospital-based-and-private-practices 